\title{
Somatostatin receptor imaging in active cardiac sarcoidosis: Would less be enough?
}

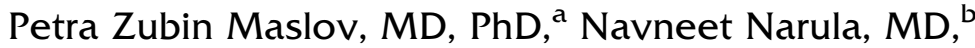 \\ and Jagat Narula, $M D, P^{a}$ \\ a Department of Cardiology, Mount Sinai St. Luke's Hospital, New York, NY \\ b Department of Pathology, New York Langone Medical Center, New York, NY
}

Received Jul 1, 2019; accepted Jul 1, 2019

doi:10.1007/s12350-019-01824-7

See related article, pp. 1089-1099

\section{THE CURRENT STUDY}

The patients with cardiac sarcoidosis are at a high risk of malignant ventricular tachyarrhythmias. The immunosuppressive therapy is effective but the diagnosis of the disease activity has remained a challenge. The assessment of the myocardial involvement is currently based on cardiac magnetic resonance imaging or nonspecific diagnosis of myocardial inflammation by PET[FDG]-CT imaging. A more specific assessment of the disease activity should be of significant clinical value. With this end in view, Bravo and colleagues evaluated the applicability of somatostatin receptor (SSTR) imaging of myocardial inflammation. ${ }^{1}$ These investigators have led the attempts at specific targeting of myocardial pathology in various disease states in the past as well.

In this feasibility experiment, investigators employed Gallium-68-labeled somatostatin (SST) analog-Dotatate (1,4,7,10-tetraazacyclododecane-1,4,7, 10-tetraacetic acid octreotate; used commonly for the assessment of neuroendocrine tumors including pheochromocytoma, paraganglioma, gastrointestinal, pancreatic, and bronchial tumors) in patients with suspected cardiac sarcoidosis based on the suggestive clinical history and abnormal myocardial FDG uptake.

Reprint requests: Jagat Narula, MD, PhD, Department of Cardiology, Mount Sinai St. Luke's Hospital, New York, NY, USA; jagat.narula@mountsinai.org

J Nucl Cardiol 2021;28:1100-4.

$1071-3581 / \$ 34.00$

Copyright (c) 2019 American Society of Nuclear Cardiology.
They reported the concordance of myocardial and extracardiac uptake of FDG with Dotatate. Of all FDG scans that showed cardiac uptake, Dotatate scans showed concordant (definite or probable abnormal) cardiac uptake in 55\%. On the other hand, FDG and Dotatate demonstrated $100 \%$ concordance in thoracic nodal activity. The Dotatate myocardial uptake was discrete but not as striking as FDG nor diffuse as FDG; the extracardiac uptake of Dotatate was rather impressive. The figures provided by the investigators speak thousand words. They propose that compared to FDG imaging, SSTR imaging might be less sensitive for the detection of myocardial inflammation, but equally effective for detecting extra-cardiac inflammation.

\section{SOMATOSTATIN RECEPTORS FAMILY}

SST, a 14-amino-acid neuropeptide, has been recognized as an important contributor to the inflammatory disease states, and its immunoregulatory characteristics have been reported in sarcoidosis and other granulomatous diseases. ${ }^{2} \mathrm{SST}$ is synthesized in the central nervous and gastrointestinal systems, endocrine glands and immune cells. ${ }^{2}$ By binding to one of the five SSTR subtypes (SSTR 1-5), somatostatin acts as a neurotransmitter, regulator of endocrine/exocrine secretion and an immunomodulator of inflammatory process. ${ }^{3}$

SSTR 1-5 belong to the family of G protein-coupled 7-transmembrane receptors (Figure 1). Although SSTR have been identified on the cell surface of many cells that participate in immune system pathways, such as macrophages, dendritic cells, and lymphocytes, their role in immunomodulation is still incompletely understood. ${ }^{4}$ SST regulates immune system responses through inhibition of cytokines secretion, de novo synthesis of interleukins, macrophage viability, phagocytosis and natural killer cell activity, ${ }^{4}$ and is thought to exhibit mostly immunosuppressive role in inflammation. In 


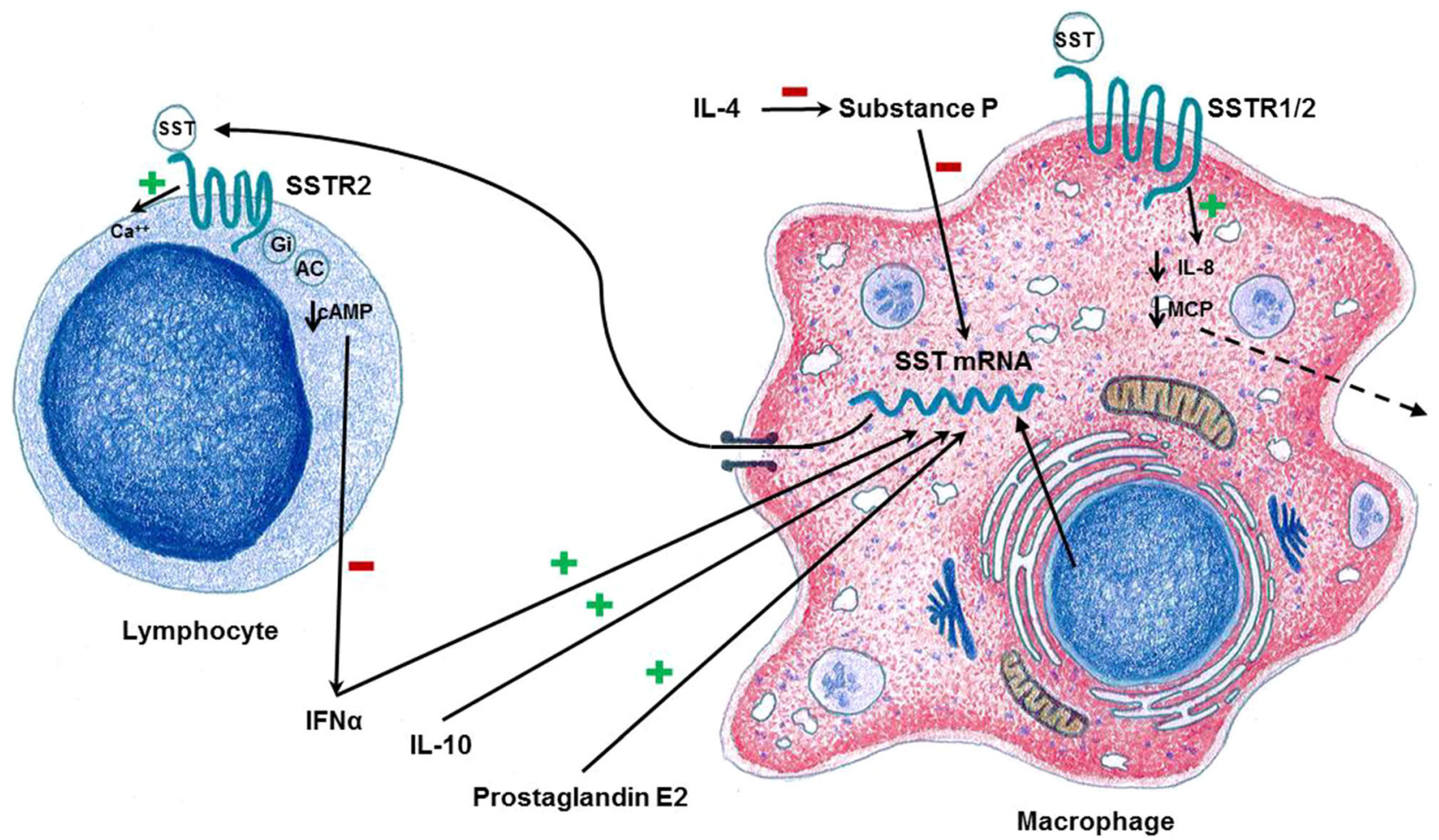

Figure 1. SSTR expression of macrophages and monocytes. The schematic figure demonstrates cytokine regulation of SST expression and its autocrine/paracrine influence. There are five different subtypes of SSTR. They belong to the family of G-protein-coupled receptors located in the cell membrane. All 5 SSTR are negatively coupled to Gi protein, leading to inhibition of adenylate cyclase and decreased level of cAMP. SSTR1 and SSTR2 are associated with tyrosine phosphatase, SSTR2 is involved in calcium channels regulation/mobilization, SSTR1 in $\mathrm{Na}^{+} / \mathrm{H}^{+}$exchanger and SSTR4 in MAP kinase regulation. SSTR5 inhibits CCK induced $\mathrm{Ca}^{2+}$ mobilization. SSTRmediated inhibition of secretory function of the cell is mostly mediated through inhibition of cAMP and calcium. Drawn by Ashish Correa MD, Mount Sinai St. Luke's Hospital, New York.

animal models, granuloma cells were found to express mRNA for SSTR2 receptor but not the other 4 SSTR subtypes. ${ }^{5}$ Binding of somatostatin to SSTR2 on granuloma cells inhibits IFN- $\gamma$ release at inflammatory site and reduces the size of granulomas in the murine model. ${ }^{5}$ Substance P and SST produced at the site of inflammation demonstrate counter-regulatory effects in immunoregulatory circuit including IFN- $\gamma$ release. Substance $\mathrm{P}$ has been shown to inhibit SST production from the granuloma macrophages at mRNA and protein levels, and specific substance $\mathrm{P}$ receptor antagonist blocks this suppression; IL-4 antagonizes the inhibitory influence of substance P on SST production. ${ }^{6}$

SSTR have been identified on $95 \%$ of normal mitogen-activated human peripheral lymphocytes. ${ }^{7}$ When $\mathrm{T}$ cell lines and B cell lines were investigated by PCR, only SSTR2 type of somatostatin receptor was expressed. Both activated macrophages as well as their precursor monocytes were shown to express mRNA for cortistatin, somatostatin-like peptide and mRNA for receptors SSTR1 and SSTR2. These receptors were localized at the cell surface of activated macrophages and are found to have inhibitory role. Production of the somatostatin within the macrophages and expression of SSTR on their cell surface at the same time potentially suggests autocrine/paracrine regulation. ${ }^{7}$ When splenic macrophages were stimulated with IFN- $\gamma$, IL-10 or prostaglandin E2, increased mRNA expression of preprosomatostatin was detected that otherwise lacked this transcription. ${ }^{8} \mathrm{CD} 4+\mathrm{T}$ lymphocytes isolated from hepatic granulomas also expressed mRNA for SSTR2. ${ }^{9}$ Basal expression of mRNA for SSTR2 has been shown to be very low in monocytes while differentiated cells such as macrophages and dendritic cells express 10-fold higher level of SSTR2 mRNA than monocytes. ${ }^{10}$ There is a difference in level of expression of SSTR in different immune cells, with highest level being on macrophages, followed by dendritic cells and the least in monocytes; the expression predominantly occurs in the activated macrophages, or their stimulated precursors. 
Activation of somatostatin receptor subtypes SSTR1 and SSTR2 with specific receptor analogs in the macrophages results in inhibition of chemokine production and decrease in viability of macrophages. ${ }^{11}$ Activation of SSTR1 and SSTR2 has been associated with decreased expression and inhibition of de novo secretion of a potent chemotactic cytokine modulatorCCL2, which regulates cells migration to the site of inflammation. SSTR are shown to be involved in regulation of another chemotactic cytokine- IL-8, or CXCL8, secreted from macrophages at the site of inflammation, which is responsible for chemotaxis of polymorphonuclear leukocytes and recruitment of monocytes. ${ }^{11}$ Activation of only SSTR2 (not SSTR1) was found to suppress production of IL-8 in LPSactivated macrophages. ${ }^{11}$ SST has been shown to be important regulator of T-cell infiltration capacity and migration properties through inhibition of chemokine stromal cell-derived factor $1 \alpha(\mathrm{SDF}-1 \alpha)$. However, application of somatostatin analogs for immunosuppression in the treatment of granulomatous disease needs to be supported by further research.

There appears to be a time course for SSTR expression per activity of the immune cells, presence of the antigen/offensive agent, and in response to immunosuppressive treatment. There is a dynamic regulation of SSTR at the membrane level by liganddependent and independent mechanisms in general, but specific data on consequences of immunosuppression on SSTR is not as clear. Somatostatin leads to desensitization of the SSTR through uncoupling of SSTR from G proteins as well as through receptor internalization and sequestration. $\beta$-Adrenergic receptor kinase is involved in desensitization of SSTR2-the receptor involved in immunosuppression activity. There are A and B isoforms of SSTR, wherein B seems to be more sensitive to receptor desensitization and its coupling efficiency to adenylyl cyclase. Binding of somatostatin (or other receptor agonist, such as Dotatate) to SSTR leads to internalization of the SSTR through clathrin-coated pits. After internalization, SSTR2 and SSTR4 are recycled back to the membrane; SSTR1 shows low agonistinduced internalization. ${ }^{12}$ The predominant expression of SSTR2 receptors in most human SST-positive neuroendocrine tumors and the efficiency of SSTR2 to undergo agonist-induced internalization is very important for the radiotherapeutic application of radiolabeled octapeptide SST-analogs.

\section{DISCUSSION}

The authors summarize that compared to FDG imaging, SSTR imaging with Dotatate may be less sensitive for the detection of myocardial inflammation in sarcoidosis. They also suggest that the Dotatate imaging was comparable to FDG for detecting extra-cardiac inflammation. They explain the lack of sensitivity of Dotatate imaging for myocardial inflammation on the basis of weak (but definitive) SSTR subtype-2 receptor immunohistochemical staining in the non-caseating granulomas in 3 explanted sarcoid hearts from the cardiac allograft recipients. However, since there was a distinct staining of SSTR in the myocardium, the authors propose the uptake to be more specific. Before preparing this editorial, we also performed SSTR2 immunostaining in the set of granulomas (Figure 2) and found the staining to be specific for cells undergoing epithelioid transformation and on the giant cells, suggesting the presence of receptors on potentially activated cells. The cells in healing granulomas including the giant cells did not demonstrate SSTR2 staining.

It should also be noted that there was a median interval of 37 [25-55] days after the FDG and before the Dotatate imaging. Notably, 4 of the 6 discordant patients were receiving immunosuppressive therapy, and only 2 of the discordant patients had nodal activity. Although the FDG uptake was always focal or focal on diffuse, and patients well prepared for glucose-based imaging, FDG imaging might carry an element of non-specificity. In such circumstances, Dotatate imaging may be more informative about the sarcoid activity. It would however be prudent to conduct a prospective study with both tests separated only by a short period of time, and correlated with the clinical characteristics of the disease. Although a combination of magnetic resonance imaging and the positron imaging has served well for characterization of cardiac sarcoidosis, ${ }^{13}$ more specific imaging agents can be of help. We have had a similar experience with SSTR imaging in past, ${ }^{14}$ wherein we performed radionuclide SSTR imaging 13 cardiac allograft recipients simultaneously with endomyocardial biopsy (EMB) to evaluate the state of myocardial inflammation. Moderate or intense radiotracer uptake was observed in eight studies. In three of these eight patients there was evidence of significant rejection on EMB (grade $2 \mathrm{R} / 3 \mathrm{~A}$ ). In the remaining five patients EMB showed only mild or no rejection, but $4 / 5$ showed significant rejection requiring treatment in the subsequent EMB performed 1 week later. The patients with low radiotracer uptake had no evidence of rejection either in the simultaneous EMB or in the EMB performed in the following week. These results indicated the feasibility of targeting activated lymphocytes with SSTR imaging in the detection of cardiac allograft rejection. SSTR imaging might predict impending rejection at least 1 week before the EMB becomes positive, and the late appearance of diagnostic EMB probably reflects a lag-time up to histological evidence of rejection becoming evident. Not only did the 

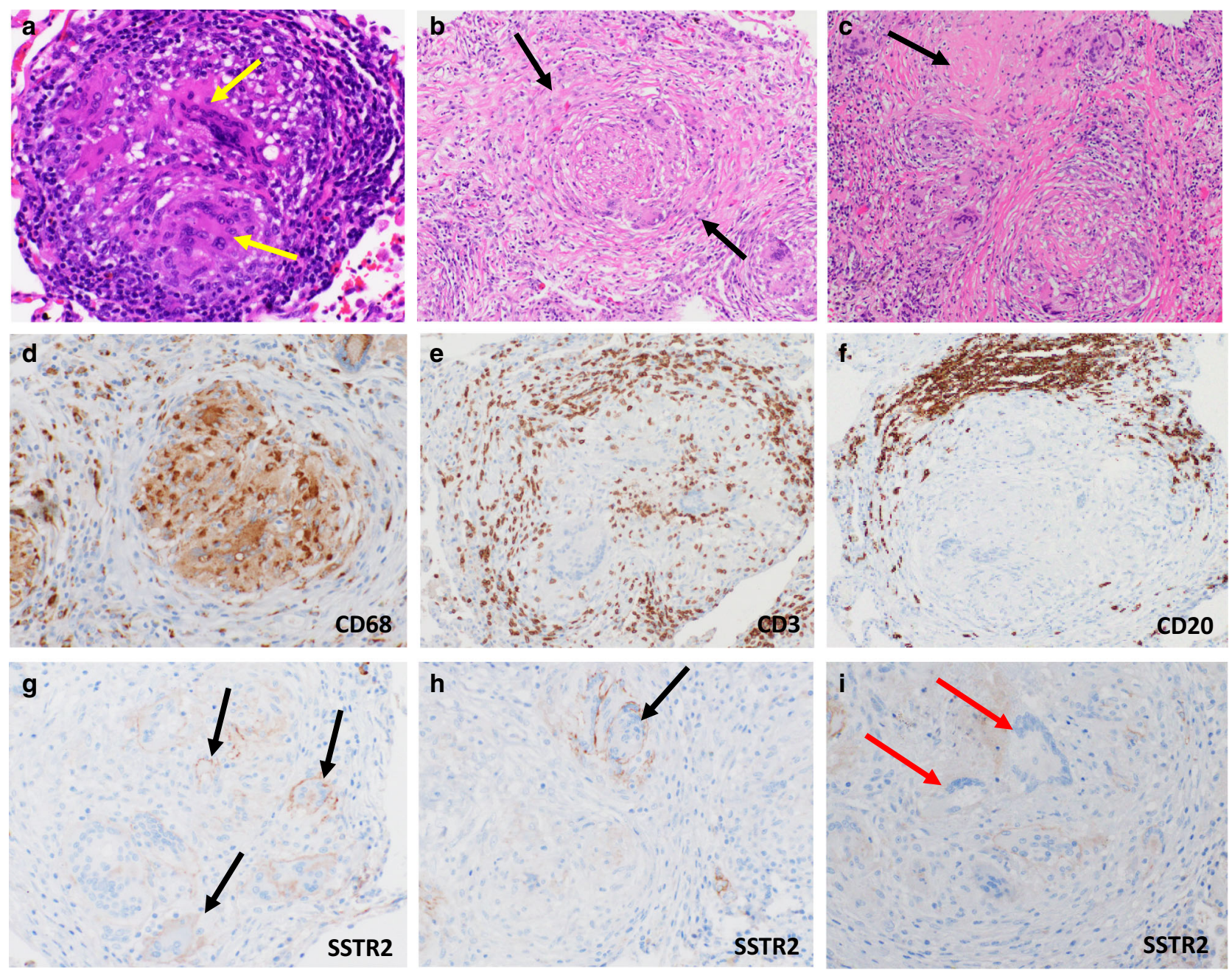

Figure 2. Sarcoid granulomas and SSTR expression. Images $\mathbf{A}, \mathbf{B}$, and $\mathbf{C}$ show compact nonnecrotizing granulomas seen in sarcoidosis consisting of epithelioid macrophages and multinucleated giant cells (yellow arrow). While the single granuloma in image $\mathbf{A}$ is surrounded by a rim of lymphocytes, those in $\mathbf{B}$ and $\mathbf{C}$ are confluent and surrounded by hyalinized collagen (black arrows). The granulomas of sarcoidosis can get progressively hyalinized as shows by the arrow in image $\mathbf{C}$. The middle panel shows that the granulomas are composed of macrophages as highlighted by CD68 immunostain (image D) and surrounded by $\mathrm{CD} 3$ positive $\mathrm{T}$ lymphocytes (image $\mathbf{E}$ ) that predominantly circumferentially surround the granuloma with few $\mathrm{T}$ lymphocytes present within the granuloma. The CD20 positive B cells are present as nodular aggregates and not present within the granuloma. The lower panel (images $\mathbf{G}-\mathbf{I}$ ) shows immunohistochemical staining for SSTR2. SSTR2 staining is patchy in the giant cells (black arrows in $\mathbf{G}$ and $\mathbf{H}$ ) and is present on the cell membrane. The giant cells in image $\mathbf{I}$ (red arrows) are negative for SSTR2. (Magnification: $\mathbf{A}$ and $\mathbf{D}, \times 40 ; \mathbf{B}, \mathbf{C}, \mathbf{E}, \mathbf{F}, \mathbf{G}-\mathbf{I}, \times 20)$.

SSTR imaging might foretell the likelihood of rejection, its interpretation at 4 hours could also allow earlier intervention in the event of rejection, given the time required for histological processing of EMB specimens. It is therefore, important that we continue to indulge in molecular imaging and fully characterize its scope in the proposed clinical states. Molecular imaging is a unique tool that allows the assessment of subcellular processes in a living organism. ${ }^{15}$ The more we indulge in molecular imaging, the more we learn about the pathogenesis, which allows development of yet better imaging strategies. We must congratulate Bravo and colleagues for the pilot study of an important clinical condition that deserves better characterization. 


\section{Disclosure}

All authors have no relationships relevant to the contents of this paper to disclose.

\section{References}

1. Bravo et al. Current JNC study 2019.

2. Weinstock JV, Elliott D. The somatostatin immunoregulatory circuit present at sites of chronic inflammation. Eur J Endocrinol 2000;143:S15-9.

3. ten Bokum AM, Hofland LJ, de Jong G, Bouma J, Melief MJ, Kwekkeboom DJ, Schonbrunn A, Mooy CM, Laman JD, Lamberts SW, van Hagen PM. Immunohistochemical localization of somatostatin receptor sst2A in sarcoid granulomas. Eur J Clin Invest 1999;29:630-6.

4. Dalm VA, van Hagen PM, van Koetsveld PM, Achilefu S, Houtsmuller AB, Pols DH, van der Lely AJ, Lamberts SW, Hofland LJ. Expression of somatostatin, cortistatin, and somatostatin receptors in human monocytes, macrophages, and dendritic cells. Am J Physiol Endocrinol Metab 2003;285:E344-53.

5. Elliott DE, Li J, Blum AM, Metwali A, Patel YC, Weinstock JV. SSTR2A is the dominant somatostatin receptor subtype expressed by inflammatory cells, is widely expressed and directly regulates $\mathrm{T}$ cell IFN-gamma release. Eur J Immunol 1999;29:2454-63.

6. Blum AM, Elliott DE, Metwali A, Li J, Qadir K, Weinstock JV. Substance $\mathrm{P}$ regulates somatostatin expression in inflammation. J Immunol 1998;161:6316-22.

7. van Hagen PM, Hofland LJ, ten Bokum AM, Lichtenauer-Kaligis EG, Kwekkeboom DJ, Ferone D, Lamberts SW. Neuropeptides and their receptors in the immune system. Ann Med 1999;31:1522 .
8. Elliott DE, Blum AM, Li J, Metwali A, Weinstock JV. Preprosomatostatin messenger RNA is expressed by inflammatory cells and induced by inflammatory mediators and cytokines. J Immunol 1998;160:3997-4003.

9. Elliott DE, Metwali A, Blum AM, Sandor M, Lynch R, Weinstock JV. T lymphocytes isolated from the hepatic granulomas of schistosome-infected mice express somatostatin receptor subtype II (SSTR2) messenger RNA. J Immunol 1994;153:1180-6.

10. Dalm VA, van Hagen PM, van Koetsveld PM, Achilefu S, Houtsmuller AB, Pols DH, van der Lely AJ, Lamberts SW, Hofland LJ. Expression of somatostatin, cortistatin, and somatostatin receptors in human monocytes, macrophages, and dendritic cells. Am J Physiol Endocrinol Metab 2003;285:E344-53.

11. Armani C, Catalani E, Balbarini A, Bagnoli P, Cervia D. Expression, pharmacology, and functional role of somatostatin receptor subtypes 1 and 2 in human macrophages. J Leukoc Biol 2007;81:845-55.

12. Hofland LJ, Lamberts SWJ. The pathophysiological consequences of somatostatin receptor internalization and resistance. Endocr Rev 2003;24:28-47.

13. Ramirez R, Trivieri M, Fayad Z, Ahmadi A, Narula J, Argulian E. Advanced imaging in cardiac sarcoidosis. J Nucl Med 2019;60:8A.

14. Aparici CM, Narula J, Puig M, Camprecios M, Martín JC, Tembl A, Flotats A, Estorch M, Catafau AM, Bernà L, Ballester M, Carrió I. Somatostatin receptor scintigraphy predicts impending cardiac allograft rejection before endomyocardial biopsy. Eur J Nucl Med 2000;27:1754-9.

15. Narula J, Dilsizian V. From better understood pathogenesis to superior molecular imaging, and back. JACC Cardiovasc Imaging 2008;1:406-9.

Publisher's Note Springer Nature remains neutral with regard to jurisdictional claims in published maps and institutional affiliations. 